\title{
UM DEBATE SOBRE O ENSINO DA SOCIOLOGIA NO EXTREMO SUL DO BRASIL
}

\author{
SCHWARZ, Vera Lúcia dos Santos (Org.). \\ Educação básica: um debate teórico sobre o ensino da sociologia. \\ Pelotas: UFPel, 2013. $111 \mathrm{p}$.
}

POR

Marcelo Pinheiro Cigales ${ }^{1}$

livro "Educação básica: um debate teórico sobre o ensino da sociologia"
organizado por Vera Schwarz, professora do curso de Ciências Sociais da
Universidade Federal de Pelotas - UFPel, é o resultado de discussões
ocorridas no primeiro Encontro Regional da Sociologia na Educação Básica,
realizado em Pelotas no ano de 2011. O evento visou discutir os diversos
problemas referentes a sociologia na Educação Básica e teve por comissão
organizadora os bolsistas do Programa Institucional de Bolsa de Iniciação à
Docência - PIBID do curso de Ciências Sociais dessa instituição.
Os cinco artigos que compõem o livro abordam questões práticas e teóricas
que envolvem o ensino de sociologia na educação básica e superior. Discussões
que de certa forma estão presentes em outros emprendimentos bibliográficos e
portanto não se restringem ao caso da UFPel, mas sim de todo o território
nacional, principalmente depois da lei no 11.684 que aprovou a obrigatoriedade

1 Doutorando em Sociologia Política pela Universidade Federal de Santa Catarina, Brasil. marcelo.cigales@gmail.com 
do ensino da sociologia na educação básica. Dessa forma, outras universidades e entidades também estão em consonância com essas discussões² .

Além disso, as pesquisas em torno do ensino da sociologia no Brasil também vêm tomando corpo, visto o aumento tanto de dossiês que reúnem artigos e resenhas como de dissertação e teses que tratam dessas questões ${ }^{3}$.

Em "o ensino da sociologia: dilemas de uma disciplina em busca de reconhecimento" Francisco Beckenkamp Vargas visa discutir algumas questões que envolvem o ensino da sociologia na educação brasileira. Através de uma análise histórica e sociológica da disciplina no país, o autor realiza observações importantes para se pensar esse processo. Dentre essas observações é possível salientar que a sociologia é uma disciplina que historicamente ocupou um lugar de menor prestígio no currículo e sua intermitência no sistema educacional agravou ainda mais a formação de professores e a produção de materiais didáticos para seu ensino. Dessa forma, um dos desafios da sociologia é conseguir realizar um trabalho motivador, fazendo uma ligação com a subjetividade dos alunos sem abdicar a referência aos conhecimentos construídos ao longo da história. De maneira geral 0 artigo entrelaça o cenário específico do ensino da sociologia com 0

\footnotetext{
${ }^{2}$ Para citar alguns exemplos a Universidade Federal do Rio Grande do Sul, criou o Laboratório Virtual e Interativo de ensino em Ciências Sociais - LAVIECS, e recentemente está publicando uma coleção sobre Ensino de Sociologia, composta por sete livros com a colaboração de diversos pesquisadores da área. A Universidade Federal do Rio de Janeiro, criou o Laboratório de Ensino de Sociologia Florestan Fernandes - LABES, que agrega a cada dois anos desde 2008, diversos pesquisadores na área do ensino de Ciências Sociais no Encontro Estadual Ensino de Sociologia no Rio de Janeiro. A Comissão de Ensino de Sociologia da Sociedade Brasileira de Sociologia, também vem realizando desde 2007 a cada dois anos o Encontro Nacional sobre o Ensino de Sociologia. A Universidade de São Paulo, criou o Laboratório de Ensino de Sociologia, assim como a Universidade Estadual de Londrina, que também é pioneira dessa discussão, tendo seu próprio laboratório de ensino, pesquisa e extensão. Outra entidade que não pode deixar de ser citada é a recém criada, Associação Brasileira de Ensino de Ciências Sociais, com filiais em quase todos os estados da federação.

Sites disponíveis em: a) <http://www.labes.fe.ufrj.br/>. b) <http://www.ufrgs.br/laviecs/site/> . c) $<$ http://ensinosociologia.fflch.usp.br/les $>$ d) $<$ http://www.uel.br/projetos/lenpes/ $>$.e) $<$ http://abecsrs.wordpress.com/estatuto-da-abecs/ $>$.

${ }^{3}$ Como exemplo disso temos nesse ano de 2014, dois dossiês sobre ensino de sociologia publicado pela Revista Café com sociologia, no site: http://revistacafecomsociologia.com /revista/index.php/revista/issue/current. E o dossiê publicado junto a Revista Teoria e Educação, UFRGS - Ensino de Sociologia: novas temáticas e experiências internacionais, no site: http://www.seer.ufrgs.br/index.php/educacaoerealidade/issue/view/2279.
} 
contexto geral da educação brasileira, primordial para se compreender o processo de produção e reprodução das disciplinas escolares ${ }^{4}$.

0 segundo artigo de Luis Fernando Minassi, "o ensino da sociologia na educação básica: a função da interdisciplinaridade no pensamento crítico", propõe discutir questões relativas à interdisciplinaridade a partir de experiências que buscam superar práticas eminentemente disciplinares. A partir da concepção dialética da educação, o autor discute a posição da sociologia e do pensamento sociológico no interior de uma educação comprometida com a emancipação dos sujeitos e empenhada com a construção do conhecimento.

Andréia Orsato apresenta o terceiro artigo intitulado "limites e desafios do ensino de sociologia: reflexões a partir de uma experiência docente.” Através de sua prática enquando docente do Instituto Federal Sul-riograndense - IFSul, a autora busca contextualizar o surgimento da disciplina de sociologia nessa instituição de ensino, bem como mostrar o panorama histórico e institucional em que a sociologia surge no país. Embora nos últimos anos a disciplina tenha se firmado em uma perspectiva crítica e contestadora do status quo, é possível afirmar que no início do século essa característica era bem distinta. Como é possível observar em outros trabalhos, como os de Oliveira (2014) e Cigales (2014), a disciplina era utilizada tanto para explicar as transformações sociais da modernidade quanto para buscar combatê-las por meio da moral cristã, dado que nesse período a disciplina suportava esse duplo sentido. Além disso, o artigo apresenta uma série de características da disciplina na atual grade curricular do curso, em específico na modalidade ligada ao curso integrado de Meio Ambiente, assim a grade curricular da disciplina propõe discutir assuntos ligados a essa temática.

Em "alternativas metodológicas ou metodologias alternativas?", Fabíola Mattos Pereira visa contextualizar, a partir de sua prática pedagógica enquanto professora de sociologia, as diferentes intepretações presentes tanto nos documentos oficiais que regulam o ensino da disciplina quanto no imaginário dos estudantes. A autora enfatiza no decorrer do texto que somente a metodologia não garante a aprendizagem. Portanto, a aula não se resume a metodologia, mas, ao que esta pode propiciar para o desenvolvimento de conteúdos e competências. No caso da sociologia o maior desafio é conseguir fazer com que os estudantes consigam contextualizar suas práticas cotidianas, os discursos e saberes do senso comum com a reflexão sociológica.

\footnotetext{
${ }^{4}$ Para análise da sociologia pelo viés da História das Disciplinas Escolares, ver o artigo de Cigales (2014).
} 
"Práticas educativa em projetos de extensão comunitária" escrito por Lucia Anello, Maria Odete Pereira, Rodrigo Pereira, Maurício da Silva Lopes e Leonardo Soares é 0 artigo que encerra 0 livro. 0 objetivo do artigo é evidenciar a importância da ação educativa que vá além dos muros da universidade e do sistema escolar. Nesse sentido a extensão cumpre papel fundamental, pois é através dela que é possível transformar a realidade de grupos sociais em situação de vulnerabilidade social. A partir dessa perspectiva os autores apresentam algumas ações desenvolvidas junto ao projeto ligado ao Monitoramento Ambiental Cidadão - LARUS da Universidade Federal do Rio Grande - FURG.

Através das temáticas apresentadas no livro é possível realizar algumas reflexões que não pretendem esgotar as possibilidades de interpretação do mesmo, mas sim servir de convite à leitura das diversas temáticas que percorrem a escrita dos capítulos, e que cada vez mais alcançam espaço no interior das Ciências Humanas. Dentre elas, é possível destacar que a trajetória de uma disciplina escolar passa por diversas instâncias, como bem aponta Bittencourt (2003, p. 10). Assim, uma disciplina esta intrinsicamente ligada à estratégia de grupos, partidos e associações que por intermédio de lutas e esforços fazem com que se consiga ascender e permanecer no currículo escolar. Como é possível observar, o caso da sociologia não foi diferente. Por vários anos ocorreram campanhas para o retorno da disciplina na educação básica. Consequentemente, sua volta aos currículos dessa modalidade de ensino reforçou ainda mais a discussão sobre diversas outras temáticas, tais como: formação de professores, valorização da licenciatura, políticas públicas, metodologias de ensino, livro didático, história da disciplina, etc.

Dessa forma, este livro integra esse processo, pois, além de estar ligado a uma política pública de fortalecimento da docência - PIBID - também representa os desafios e angústias dos professores ligados ao ensino da disciplina. Assim, "Educação Básica: um debate teórico sobre o ensino da sociologia" deixa para as gerações que estão se formando um registro histórico das especificidades da sociologia no extremo sul do país. 0 que se espera é que estas discussões se desenvolvam e amadureçam, para que a sociologia se fortaleça enquanto disciplina escolar, capaz de formar sujeitos reflexivos e conscientes de seus direitos e deveres enquanto cidadãos, comprometidos com o bem estar coletivo. 


\section{REFERÊNCIAS}

BITTENCOURT, Circe M.F. Disciplinas escolares: história e pesquisa. In: OLIVEIRA, Marcus A. T. de. RANZI, Serlei M. Fischer. (Org.). História das disciplinas escolares no Brasil: contribuições para o debate. Bragança Paulista: EDUSF, 2003. CIGALES, Marcelo Pinheiro. 0 ensino da sociologia no Brasil: perspectiva de análise a partir da história das disciplinas escolares. Revista Café com Sociologia, Piúma/ES, v. 3, n. 1, p. 49-67, 2014. Disponível em:

$<$ http://revistacafecomsociologia.com/revista/ index.php/revista/article/view/100 > . Acesso em: 20 abr. 2014.

OLIVEIRA, Amurabi. Revisitando a história do ensino da sociologia na educação básica. Acta Scientiarum. Education, Maringá, v. 35, n. 2, p. 179-189, jul./dez. 2013. Disponível em:

$<$ http://periodicos.uem.br/ojs/index.php/ActaSciEduc/article/view/20222/11790 $>$. Acesso em: 20 abr. 2014. 